\title{
Dietary intake of nutrients of great interest in immunonutrition to prevent muscle damage in soccer players
}

\author{
C. Conejos ${ }^{1,2}$, A. Giner ${ }^{2}$, J. Mañes $^{1}$ and J. M. Soriano ${ }^{1}$ \\ ${ }^{1}$ Laboratory of Nutrition, Faculty of Pharmacy, University of Valencia, Av. Vicent Andrés Estellés s $/ n, 46100$, \\ Burjassot, Spain and ${ }^{2}$ Valencia C,. Ciudad Deportiva, 46980 Paterna, Spain
}

Soccer is a sport in which players are exposed to long-term periods of training and players need to augment strength and fat-free mass gains by resistance training, minimize muscle damage and soreness and help to improve endurance. Recently, the incidence of injuries has increased during and preceding soccer matches, which influences the effectiveness of the team. One study ${ }^{(1)}$ has reported that muscle injury resulting from intensive exercise triggers the immune response of Ig and complement in serum, and induces the inflammatory reaction. Although neutrophil reactive oxygen species (ROS) production is thought to play a part in clearance of phagocyte-damaged host tissue, such as muscle tissue, by exercise ${ }^{(2)}$, oxidative stress has been associated with decreased physical performance, muscular fatigue, muscle damage, and overshooting inflammation ${ }^{(3)}$. In a well-trained player a good diet can enhance physical and athletic performance and decrease the incidence of injuries during soccer matches. The repetition of intense exercise diminishes the neutrophil inflammatory reaction, and the recovery from physical damage may be delayed ${ }^{(4)}$. However, it has been observed that carbohydrate ingestion has only a minimal influence on the immune response to exercise ${ }^{(5)}$. It has been suggested that 4 weeks of Fe supplementation significantly increases body $\mathrm{Fe}$ stores and inhibits the decrease in $\mathrm{Hb}$ concentration induced by soccer training ${ }^{(6)}$. The objective of the present study was to evaluate the dietary intake of nutrients of relevance to immunonutrition in relation to muscle damage in young high-level soccer players (group A: $n$ 20, age 17-18 years; group B: $n$ 22, age 20-24 years). The $24 \mathrm{~h}$ diet-record method was used by the dietitian of the soccer club to analyse the dietary intake of arginine, branched-chain amino acids (valine, leucine and isoleucine), $\mathrm{Zn}, \mathrm{Cu}, \mathrm{Fe}, \mathrm{Se}, \mathrm{Mg}$ and vitamins $\mathrm{A}, \mathrm{C}$ and $\mathrm{E}$.

The results showed that $65 \%$ of the players between 20 and 24 years of age had intakes below the Spanish and European recommended intakes (SERI) for $\mathrm{Zn}$ and $\mathrm{Mg}$, whereas approximately $60 \%$ of the youngest players were below the SERI only for Zn. Nevertheless, if results were compared with recommended values for sportsmen (SRV), $>65 \%$ of both groups failed to achieve the SRV for Fe, Zn and vitamins $\mathrm{A}, \mathrm{C}$ and $\mathrm{E}$.

In conclusion, the results show that the group of players studied need to include in their diet foods containing antioxidant vitamins, Fe and $\mathrm{Zn}$ in order to prevent possible muscle damage. Currently, a nutritional education programme is being developed to promote an appropriate food pattern to aid the reduction of lesions in soccer players.

The work was supported by University of Valencia (UV-AE-20070219).

1. Mashiko T, Umeda T, Yamamoto Y \& Sugawara K (2004) Br J Sports Med 38, 617-621.

2. Peake J \& Suzuki K (2004) Exerc Immunol Rev 10, 129-141.

3. König D, Wagner KH, Elmadfa I, Berg A (2001). Exercise and oxidative stress: significance of antioxidants with reference to inflammatory, muscular, and systemic stress. Exerc Immonol Rev 7: 108-33.

4. Rebelo AN, Candeias JR, Fraga MM, Duarte JA, Soares JM, Magalhaes C \& Torrinha JA (1998) J Sports Med Phys Fitness 38, $258-261$.

5. Bishop NC, Blannin AK, Robson, PJ, Walsh NP \& Gleeson M (1999) J Sports Sci 17, 787-796.

6. Kang HS \& Matsuo T (2004) Asia Pac J Clin Nutr 13, 353-358. 